\title{
Tumor-penetrating peptide fused EGFR single-domain antibody enhances radiation responses following EGFR inhibition in gastric cancer
}

\author{
FUZHI JI ${ }^{1-3^{*}}$, HUIZI SHA ${ }^{2 *}$, FANYAN MENG ${ }^{2}$, ANQING ZHU ${ }^{2}$, NAIQING DING ${ }^{2}$, \\ HANG ZHANG ${ }^{2}$, HUI XU ${ }^{4}$, HANQING QIAN ${ }^{2}$, LIXIA YU ${ }^{2}$, QIZHAN LIU ${ }^{4}$ and BAORUI LIU ${ }^{1,2}$ \\ ${ }^{1}$ The Comprehensive Cancer Centre of Nanjing Drum Tower Hospital, Clinical College of Nanjing Medical University; \\ ${ }^{2}$ The Comprehensive Cancer Centre of Drum Tower Hospital, Medical School of Nanjing University and \\ Clinical Cancer Institute of Nanjing University, Nanjing, Jiangsu 210008; ${ }^{3}$ Department of Radiotherapy Oncology, \\ Huai'an Hospital Affiliated of Nanjing Medical College and Huai'an First People's Hospital, Huai'an, Jiangsu 223000; \\ ${ }^{4}$ Institute of Toxicology, School of Public Health, Nanjing Medical University, Nanjing, Jiangsu 211166, P.R. China
}

Received January 20, 2018; Accepted June 12, 2018

DOI: $10.3892 /$ or.2018.6532

\begin{abstract}
Radiotherapy has been the primary method for the local control of several types of unresectable tumor, including gastric cancer. Patients with gastric cancer frequently express high levels of epidermal growth factor receptor (EGFR), which have been found to increase following radiotherapy treatment. This provides a basis for the combination of antibodies targeting EGFR and radiotherapy. In our previous study, a protein (anti-EGFR-iRGD) with bispecific targets and high permeability was constructed, and its effects on inhibiting the proliferation of gastric cancer cells was investigated. In the present study, the capacity of anti-EGFR-iRGD to modulate a radiation response was investigated and the specific mechanisms underlying these interactions were evaluated in gastric cancer cell lines and xenografts exhibiting high levels of EGFR. The radioenhancement of anti-EGFR-iRGD was associated
\end{abstract}

Correspondence to: Dr Baorui Liu, The Comprehensive Cancer Centre of Nanjing Drum Tower Hospital, Clinical College of Nanjing Medical University, 321 Zhongshan Road, Nanjing, Jiangsu 210008, P.R. China

E-mail: baoruiliu@nju.edu.cn

Professor Qizhan Liu, Institute of Toxicology, School of Public Health, Nanjing Medical University, 101 Longmian Avenue, Jiangning, Nanjing, Jiangsu 211166, P.R. China

E-mail: drqzliu@hotmail.com

${ }^{*}$ Contributed equally

Abbreviations: EGFR, epidermal growth factor receptor; TKI, tyrosine kinase inhibitor; LSCM, laser scanning confocal microscopy

Key words: gastric cancer, radiotherapy, recombinant protein, iRGD, anti-epidermal growth factor receptor, single-domain antibody with inhibited radiation-induced upregulation of EGFR, inhibited cell proliferation and promotion of cell apoptosis. In addition, anti-EGFR-iRGD appeared to permeate more into the tumor tissue following radiation. These findings indicated that the recombinant protein anti-EGFR-iRGD was a selective and effective radiosensitizer in EGFR-overexpressing gastric cancer cells and xenografts. These results further suggested that anti-EGFR-iRGD is a potential superior EGFR-targeted therapy combined with radiotherapy. Overall, the present study suggested that anti-EGFR-iRGD may be a promising candidate for preclinical and clinical use.

\section{Introduction}

Gastric cancer is the fourth most common malignant tumor worldwide and the second leading cause of cancer-associated mortality (1), $70 \%$ of which occur in developing regions, including $40 \%$ of individuals in China (2). Despite advances in cancer therapy, the majority of advanced malignancies remain incurable. Radiotherapy is the main method of local control for several types of unresectable tumor, and for controlling gastric bleeding. Previous studies have shown that radiotherapy did not improve the survival rate of patients with gastric cancer, whereas local control rates were $70 \%$ (3). Radiotherapy is considered an attractive modality for the high incidence of locoregional failures following surgical treatment of gastric cancer $(4,5)$.

Tumors in humans frequently express high levels of epidermal growth factor receptor (EGFR), which has been associated with poor prognosis when expressed at high levels (6). In 511 cases of gastric carcinoma, the expression of EGFR was $27.4 \%$ (7). In several cases, including gastric cancer, the overexpression of EGFR drives tumor cells towards uncontrolled proliferation, allowing the cells to evade programmed death, thereby enhancing their ability to migrate and metastasize. The activation of EGFR is involved in the resistance of tumor cells to radiotherapy (8). In response to radiation, EGFR is rapidly activated and induces several 
downstream signaling pathways, including mitogen-activated protein kinase (MAPK)-extracellular signal regulated kinase (ERK) and phosphoinositide 3-kinase (PI3K)/Akt. Activation of these signaling pathways may promote cell proliferation and apoptosis avoidance, and the repair of radiation-induced DNA damage through homologous and non-homologous recombination (9). Repeated exposure to radiation also results in increased expression of EGFR $(9,10)$. Therefore, EGFR inhibitors are the most promising molecular targeting agents for use in combination with radiotherapy (11-13). Advances in the field of genetic engineering have led to the development of various EGFR inhibitors, including monoclonal antibodies, tyrosine kinase inhibitors (TKIs), antisense oligonucleotides and single-domain antibody (14). In a previous study, the application of cetuximab during primary radiotherapy in patients with head and neck squamous cell carcinoma resulted in improved locoregional tumor control and survival rates compared with patients who received radiotherapy alone (11). These pioneering findings have paved the way for the clinical use of EGFR inhibitors in combination with radiotherapy.

In our previous study, a tumor-penetrating peptide was constructed that was fused with an EGFR single-domain antibody (15), termed anti-EGFR-iRGD, which consisted of an anti-EGFR VHH, from the variable domain of the heavy chain of the antibody, fused to iRGD. The tumor specific binding peptide exhibited high permeability into the tumor. In addition, the recombinant protein anti-EGFR-iRGD showed antitumor activity in tumor cell lines, multicellular spheroids and mice (16). Radiotherapy is widely used in the treatment of various types of cancer. In the present study, the effects of anti-EGFR-iRGD treatment in combination with radiotherapy were investigated in gastric cancer with high levels of EGFR.

\section{Materials and methods}

Cell culture, xenograft experiments and ionizing radiation. Three human gastric adenocarcinoma cell lines (SNU-719, BGC-823 and HGC-27) were maintained in Roswell Park Memorial Institute (RPMI)-1640 medium (Invitrogen; Grand Island, NY, USA) supplemented with $10 \%$ bovine calf serum (BCS; Life Technologies/Gibco, Grand Island, NY) in 5\% $\mathrm{CO}_{2}$ at $37^{\circ} \mathrm{C}$. All animal procedures were performed in compliance with the guidelines set by the Animal Care Committee at Drum Tower Hospital (Nanjing, China). A total of 5,000,000 BGC-823 gastric cancer cells in $0.1 \mathrm{ml}$ of PBS were subcutaneously injected in the lower right flank of athymic nude BALB/c mice (5-6 weeks old, female, 18-22 g, Shanghai Experimental Animal Center, Shanghai, China). BALB/c mice were kept in climate-controlled quarters with a 12-h light and dark cycle with food and water in cages under germ-free conditions. Tumor volumes were calculated from two diameter measurements according to the following formula: Tumor volume $=\left(\right.$ length $\mathrm{x}$ width $\left.^{2}\right) / 2$. Radiotherapy was administered in vitro using a $6 \mathrm{MeV} \mathrm{X}$-ray linear accelerator (Elekta AB, Stockholm, Sweden).

Cell viability assay and flow cytometry assays. Following treatment with anti-EGFR-iRGD, cell viability was evaluated using an MTT assay. In brief, the cells were seeded into 96-well plates at a density of 3,000-8,000 cells/well. Subsequently, cells in the logarithmic phase were treated with anti-EGFR-iRGD at indicated concentrations $(6.3,12.5,25,50,100,200,400$ and $800 \mu \mathrm{g} / \mathrm{ml})$. Following incubation for $24 \mathrm{~h}$ at $37^{\circ} \mathrm{C}$, MTT reagent was added, followed by dimethyl sulfoxide (DMSO), and the spectrophotometric absorbance was measured $(490 \mathrm{~nm})$. To detect apoptosis, cells in the logarithmic phase were treated with anti-EGFR-iRGD for $24 \mathrm{~h} 37^{\circ} \mathrm{C}$. The cells were harvested, washed with PBS, and subsequently incubated in the dark for $15 \mathrm{~min}$ at room temperature. Finally, the degree of apoptosis was analyzed by FACScan laser flow cytometry (BD Aria II; BD Biosciences, Franklin Lakes, NJ, USA) using an FITC Annexin V Apoptosis Detection kit (Roche Applied Science, Indianapolis, IN, USA). The number of cells analyzed for each sample was 50,000.

Clonogenic survival assay. The cells were seeded into 6-well plates at a density of 500-8,000 cells per well. Following incubation for $24 \mathrm{~h}$, anti-EGFR-iRGD $(100 \mu \mathrm{g} / \mathrm{ml})$ was added into each well. The cells were treated with anti-EGFR-iRGD for $24 \mathrm{~h}$ at $37^{\circ} \mathrm{C}$ and then exposed to increasing doses of ionizing radiation (0, 2, 4, 6 and $8 \mathrm{~Gy})$. Following intervals of 7-10 days, cell colonies (consisting of $\geq 50$ cells) were stained with crystal violet and counted manually using optical microscopy.

Western blot assay. The expression levels of EGFR in gastric cancer cells were confirmed by western blot analysis. Cell lysates were prepared with a detergent buffer, as previously described (17). Protein concentrations were measured with the BCA Protein Assay according to the manufacturer's manual (Beyotime Institute of Biotechnology, Shanghai, China). The proteins $(30 \mu \mathrm{g})$ were separated by $10 \%$ SDS-PAGE, and transferred onto polyvinylidene difluoride membranes (EMD Millipore, Billerica, MA, USA). The membranes were blocked with $5 \%$ bovine serum albumin (BSA; Life Technologies/Gibco) in Tris-buffered saline, containing $0.05 \%$ Tween-20 for $2 \mathrm{~h}$ at room temperature, and then incubated overnight at $4^{\circ} \mathrm{C}$ with a $1: 2,000$ dilution of primary antibody targeting EGFR (dilution 1:2,000; cat. no. 4267; Cell Signaling Technology, Inc., Danvers, MA, USA) and $\beta$-actin (dilution 1:2,000; cat. no. AF0003; Beyotime Institute of Biotechnology, Haimen, China). The membranes were incubated with a 1:2,000 dilution of horseradish peroxidase-conjugated goat anti-mouse (1:2,000; cat. no. A0216; Beyotime Institute of Biotechnology) and goat anti-rabbit antibodies (dilution 1:2,000; cat. no. A0208; Beyotime Institute of Biotechnology) for $1 \mathrm{~h}$ at room temperature and detected by ECL reagents (Bio-Rad Laboratories, Inc., Hercules, CA, USA).

Penetration in tumor tissue. Following radiation, the distribution of anti-EGFR-iRGD in tumor tissues was determined by laser scanning confocal microscopy (LSCM). Animal models were used to locate proteins and the permeability of recombinant proteins following radiotherapy was examined. The BALB/c mice ( $n=3$ mice per group) were subcutaneously injected with EGFR-overexpressing BGC-823 cells $(5,000,000$ gastric cancer cells in $0.1 \mathrm{ml}$ of PBS), in the right flank (no radiation, $0 \mathrm{GY}$ ) and in the left flank (radiation, single dose of $2 \mathrm{~Gy}$ ). When the tumors reached a volume of $\sim 150 \mathrm{~mm}^{3}$, radiotherapy was delivered to the left flank at $600 \mathrm{cGy} / \mathrm{min}$ with $6 \mathrm{MV} \mathrm{X}$-rays. The mice received a 


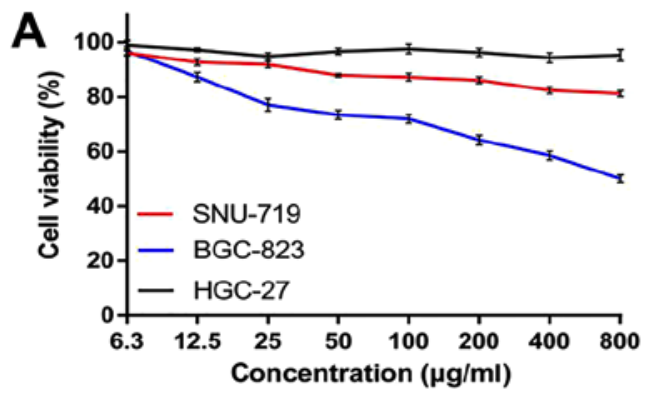

B
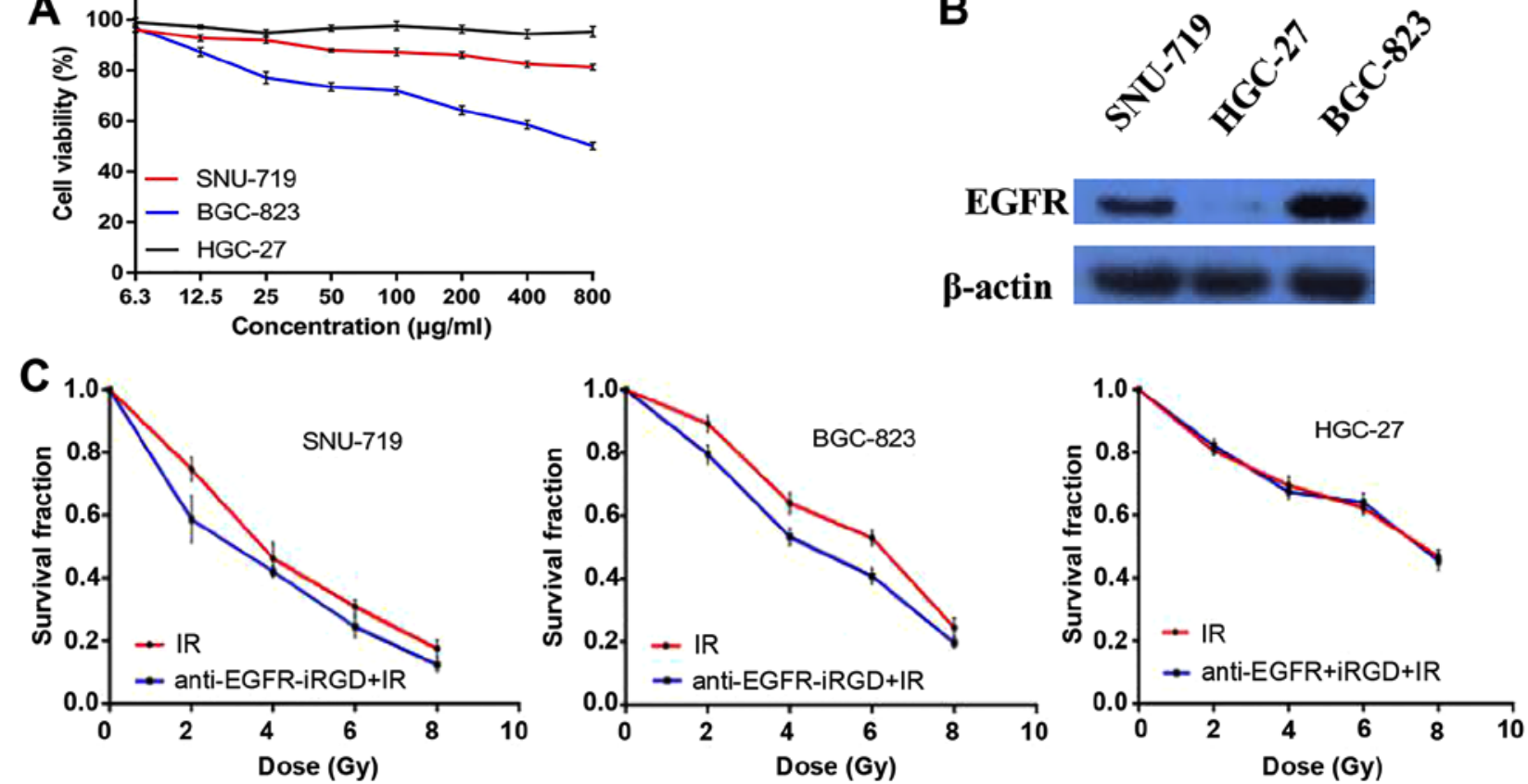

Figure 1. Cytotoxicity of anti-EGFR-iRGD, expression levels of EGFR and effect on radiation response. (A) Anti-EGFR-iRGD at various doses was added to SNU-719, BGC-823 or HGC-27 cells and incubated for $24 \mathrm{~h}$. (B) Western blot analysis of whole lysates for expression of EGFR and $\beta$-actin. (C) Effect of anti-EGFR-iRGD on radiosensitivity was examined by clonogenic survival in SNU-719, BGC-823 and HGC-27 gastric cancer cells following exposure to radiation $(2,4,6$ and $8 \mathrm{~Gy})$. Cells were exposed to anti-EGFR-iRGD $(100 \mu \mathrm{g} / \mathrm{ml})$ for $24 \mathrm{~h}$ prior to the onset of radiation. Control cells received radiation without anti-EGFR-iRGD treatment. Data are expressed as the mean \pm standard deviation. EGFR, epidermal growth factor receptor; IR, ionizing radiation.

single dose of 2 Gy. At 24 h post-radiation treatment, rhodamine-B-labeled anti-EGFR-iRGD was administered to the BGC-823 tumor-bearing mice via tail vein injection. The mice were sacrificed and tumors were harvested $1 \mathrm{~h}$ following the administration of anti-EGFR-iRGD. The tumors were frozen and sections were cut. Finally, the tumor sections $(5 \mu \mathrm{m})$ were subjected to DAPI staining and visualized using LSCM.

In vivo antitumor effect. The gastric cancer cells (BGC-823) were subcutaneously injected into BALB/c mice. When the subcutaneous tumor was $\sim 100 \mathrm{~mm}^{3}$, the mice were randomly divided into four groups. The day of randomization was designated as 'Day 1'. The mice were treated every day by intraperitoneal injection with anti-EGFR-iRGD at $1 \mathrm{mg}$ on the first day (day 1) and either $0.6 \mathrm{mg}$ during each subsequent injection (a total of five injections). At $24 \mathrm{~h}$ following the first injection, radiotherapy was delivered to one field, including the tumor, with 5-mm margins, using a Clinac $2300 \mathrm{C} / \mathrm{D}$ linear accelerator. Radiation was delivered at $600 \mathrm{cGy} / \mathrm{min}$ with $6 \mathrm{MV}$ X-rays beams at doses of $10 \mathrm{~Gy}$, in five fractions, with one fraction each day. The mice were monitored daily, and tumor volume and body weight were recorded every 3 days. The mice were sacrificed at the end of the experiment. Following treatment, histological observation of the heart, liver, spleen, lung and kidney, and tumor tissues was performed.

Immunostaining of tumor sections and organs. The xenografts and organs were fixed in neutral buffered formalin, embedded in paraffin, and stained with hematoxylin and eosin (H\&E) for pathological observation. The tissues were sectioned at a thickness of $5 \mu \mathrm{m}$ and the sections were evaluated using optical microscopy.
Statistical analysis. SPSS 20.0 software (IBM SPSS, Armonk, NY, USA) was used for statistical analysis. T-test was used to compare the means between two groups, where their variances of both groups may be different. One-way analysis of variance was used for multiple comparisons. Covariance analysis was used for comparison between four groups to remove the effects of the covariate. $\mathrm{P}<0.05$ was considered to indicate a statistically significant difference. Data are presented as the mean \pm standard deviation .

\section{Results}

In vitro cytotoxicity of recombinant protein anti-EGFR$i R G D$ and expression of EGFR in gastric cancer cell lines. In vitro cytotoxicity was assessed using MTT assays, which showed that, even at a low concentration, anti-EGFR-iRGD exhibited anti-proliferative activity against the SNU-719 cells and BGC-823 cells. Furthermore, a dose-dependent effect of anti-EGFR-iRGD was observed in the SNU-719 cells and BGC-823 cells. However, in the HGC-27 cells (no EGFR expression), no anti-proliferative activity was observed, even at the highest concentration of $800 \mu \mathrm{g} / \mathrm{ml}$ (Fig. 1A). To select appropriate cell lines as the study objective and to investigate the expression levels of EGFR in different gastric cancer cell lines, the three human gastric cancer cell lines (SNU-719, BGC-823 and HGC-27) were evaluated by western blot analysis. The data revealed the following descending expression levels of EGFR: BGC-823>SNU-719>HGC-27 (Fig. 1B). These findings indicated that the anti-proliferative activity of anti-EGFR-iRGD in human gastric cancer cells was associated with the expression of EGFR. 
A
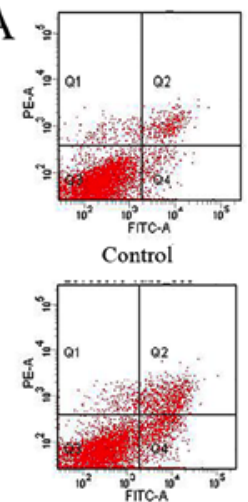

IR

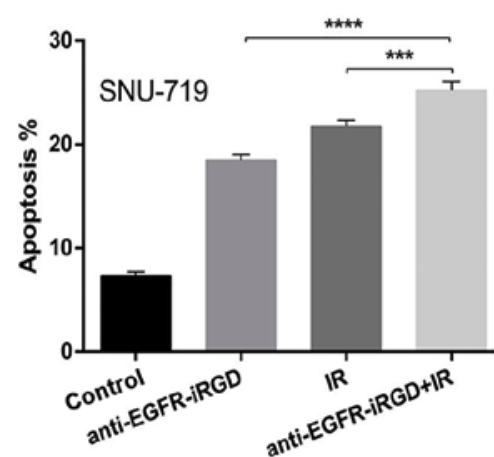

$\mathrm{B}$

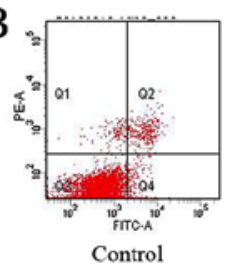

anti-EGFR-iRGD

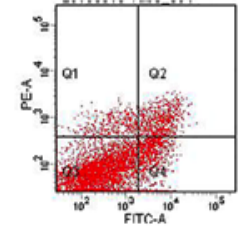

anti-EGFR-iRGD+IR

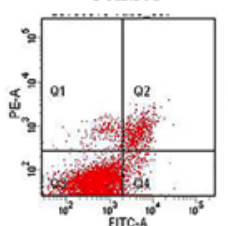

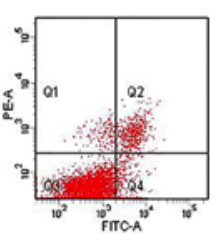

anti-EGFR-iRGD

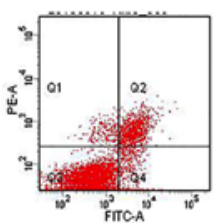

anti-EGFR-iRGD+IR
$\mathrm{C}$
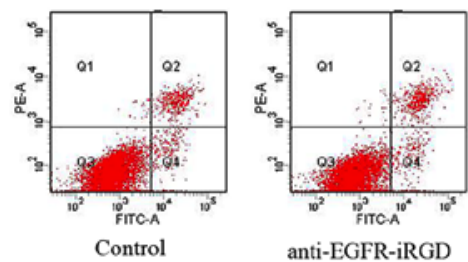

anti-EGFR-iRGD

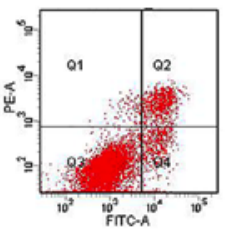

IR

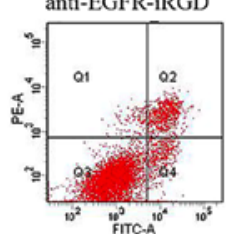

anti-EGFR-iRGD+IR
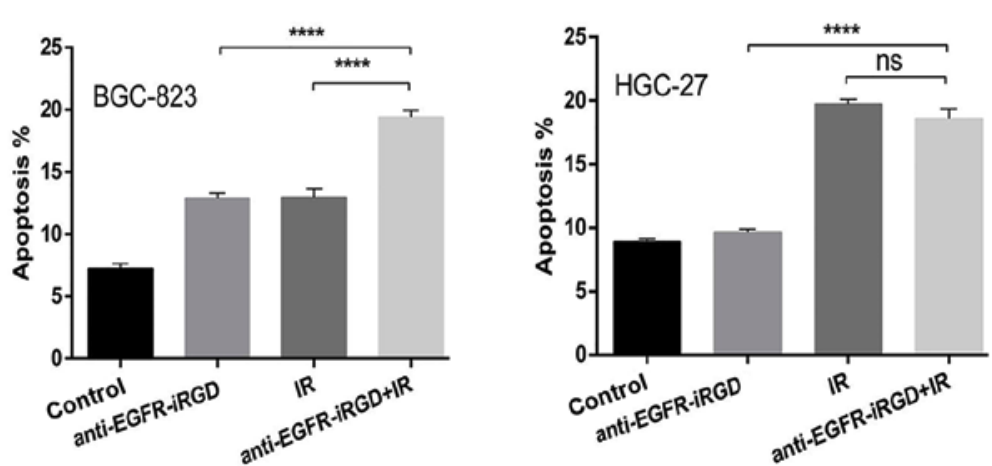

Figure 2. Anti-EGFR-iRGD combined with IR significantly induces apoptosis. Following treatment with anti-EGFR-iRGD (100 $\mu$ g/ml) in combination with IR (6 Gy), the degree of apoptosis of BGC-823 cells was investigated by flow cytometry. The rate of apoptosis was determined as follows: Apoptosis $\left.=(\mathrm{Q} 2+\mathrm{Q} 4) /(\mathrm{Q} 1+\mathrm{Q} 2+\mathrm{Q} 3+\mathrm{Q} 4) .{ }^{* * * *} \mathrm{P}<0.0005,{ }^{* * * * *} \mathrm{P}<0.0001\right)$. EGFR, epidermal growth factor receptor; IR, ionizing radiation; ns, not significant.

Anti-EGFR-iRGD modulates radiosensitivity. To evaluate the potential capacity of combining anti-EGFR-iRGD with radiation in human gastric cancer cells, experiments were performed to examine the effect of anti-EGFR-iRGD on clonogenic survival. The clonogenic survival curves of SNU-719, BGC-823 and HGC-27 cells are shown in Fig. 1C, in which cells were exposed to anti-EGFR-iRGD and radiation (anti-EGFR-iRGD prior to radiation). The data indicated that treatment with anti-EGFR-iRGD prior to radiation induced modest but consistent radiosensitization, as manifested by a reduction in clonogenic survival compared with control exposure to ionizing radiation alone, in SNU-719 and BGC-823 cells treated with 2, 4, 6 and 8 Gy.

Anti-EGFR-iRGD enhances radiation-induced apoptosis. To investigate the inhibitory effects of the combination treatment of anti-EGFR-iRGD \pm radiation on cell growth, the apoptotic responses of recombinant proteins combined with ionizing radiation (single dose of $6 \mathrm{~Gy}$ ) were investigated in SNU-719, BGC-823 and HGC-27 gastric cancer cells. Q2 represents early apoptotic cells, Q2+Q4 indicates gastric cells that are not viable. Compared with the cells that received ionizing radiation alone or recombinant protein alone, the SNU-719 cells (Fig. 2A) and BGC-823 cells (Fig. 2B) pretreated with anti-EGFR-iRGD protein showed a significant increase in apoptosis $(\mathrm{P}<0.0001)$. However, compared wit the cells that received ionizing radiation alone, the HGC-27 cells (Fig. 2C) pretreated with anti-EGFR-iRGD protein did not show an increase in apoptosis $(\mathrm{P}>0.05)$. These findings indicated that the recombinant protein-enhanced apoptosis of human gastric cancer cells was associated with the expression of EGFR.

Mechanism of recombinant protein enhances the radiation response. Following ionizing radiation for $24 \mathrm{~h}$, the expression of EGFR in tumor tissue sections was analyzed. The expression pattern revealed mainly membrane-bound EGFR staining, indicating that, following ionizing radiation, EGFR was upregulated (Fig. 3A). As shown in Fig. 3B, the increased upregulation of EGFR was confirmed following radiation exposure (single dose of $2 \mathrm{~Gy}$ ) in the BGC-823 cell lines. The radiation-induced upregulation of EGFR was inhibited by pretreatment of the tumor cells with $100 \mu \mathrm{g} / \mathrm{ml}$ anti-EGFR-iRGD for $24 \mathrm{~h}$. These findings showed that anti-EGFR-iRGD treatment combined with radiotherapy effectively inhibited the expression of EGFR in EGFR-overexpressing gastric cancer cells.

Evaluation of the penetration of anti-EGFR-iRGD into tumor tissue following radiotherapy. BALB/c mice were subcutaneously injected with BGC-823 cells, in the right flank (no radiation, $0 \mathrm{~Gy}$ ) and in the left flank (radiation, $2 \mathrm{~Gy}$ ). The penetration ability of recombinant protein anti-EGFR-iRGD following radiotherapy was then analyzed with tumor tissue sections derived from BGC-823-bearing mice. The penetration of anti-EGFR-iRGD was also evaluated in BGC-823 tumors at $1 \mathrm{~h}$ post-injection and following radiation ( $2 \mathrm{~Gy}$ ) for $24 \mathrm{~h}$. Rhodamine B-labeled proteins (red) and DAPI-labeled nuclei (blue) were present in the images of tumor sections. Following radiation with 2 Gy for $24 \mathrm{~h}$, the penetration 
A

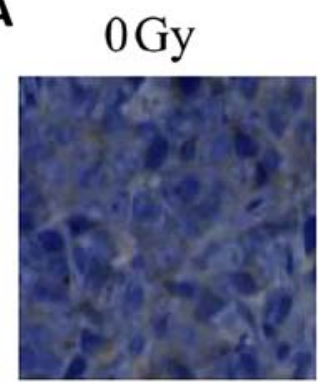

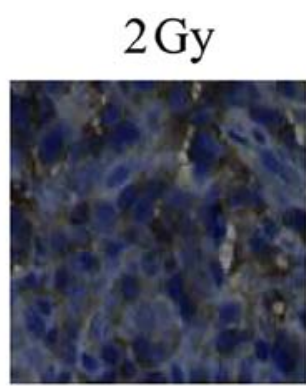

B

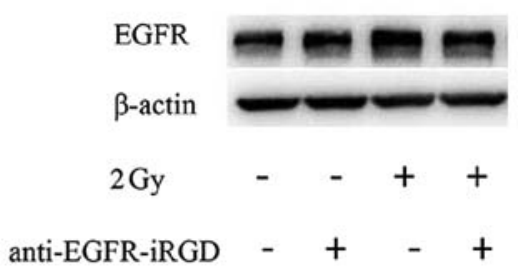

C
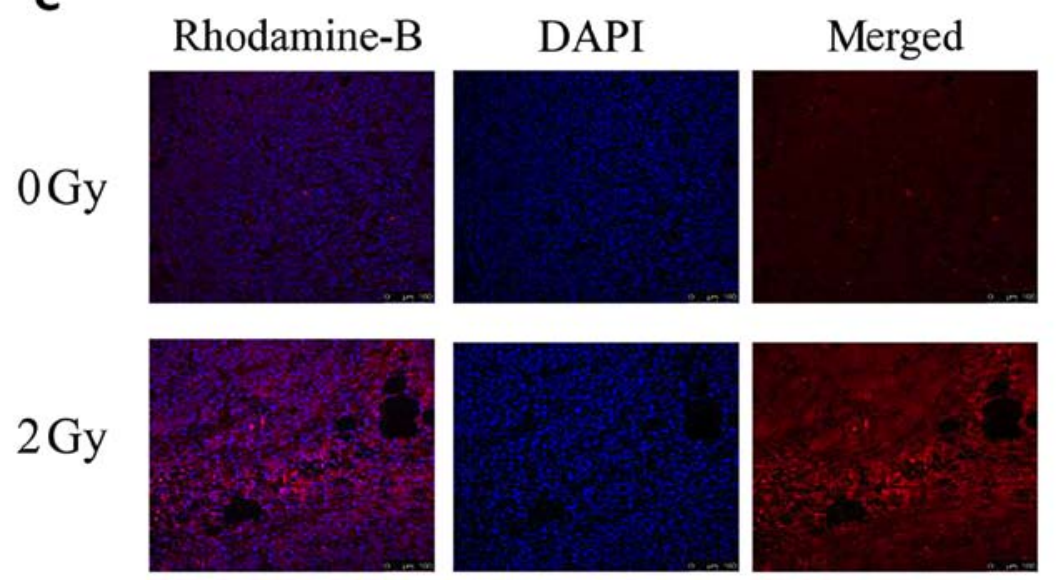

Figure 3. Effect of radiation on the expression of EGFR, anti-EGFR-iRGD-induced inhibition of radiation-induced upregulation of EGFR, and evaluation of anti-EGFR-iRGD penetration in BGC-823 tumors. (A) Immunohistochemical staining of tumor tissue sections from BGC-823 tumor-bearing mice following treatment with radiation (0 or 2 Gy). Following single IR for $24 \mathrm{~h}$, expression of EGFR was upregulated. Positive (yellow) staining indicates EGFR (magnification, x100). (B) Effect of anti-EGFR-iRGD treatment on expression of EGFR following radiation exposure. BGC-823 cells $\pm 24 \mathrm{~h}$ pretreatment with anti-EGFR-iRGD $(100 \mu \mathrm{g} / \mathrm{ml})$ were harvested $24 \mathrm{~h}$ following radiation exposure (single dose of 2 Gy). Whole cell lysates were evaluated for total levels of EGFR. (C) BALB/c mice were subcutaneously injected with BGC-823 cells, in the right flank (no radiation, 0 Gy) and in the left flank (radiation, 2 Gy). Anti-EGFR-iRGD penetration was evaluated in tumors at $1 \mathrm{~h}$ post-injection and following radiation of $2 \mathrm{~Gy}$ for $24 \mathrm{~h}$. After $24 \mathrm{~h}$ of radiation, penetration of anti-EGFR-iRGD into the tumor tissues was increased. Rhodamine B-labeled proteins (red), nucleus (blue). (magnification, x400). EGFR, epidermal growth factor receptor.

of anti-EGFR-iRGD into the tumor tissues had increased (Fig. 3C).

Anti-EGFR-iRGD augments the in vivo tumor response of gastric cancer xenografts to radiation. The in vivo activity of anti-EGFR-iRGD \pm radiation in tumor xenografts was examined. BGC-823 $\left(5 \times 10^{6}\right)$ cells were injected subcutaneously into the flank of at hymic mice. The mice were treated with PBS (control) or anti-EGFR-iRGD (1.0 mg on the first day, $0.6 \mathrm{mg}$ every day from day $2-5$ via intraperitoneal injection), ionizing radiation (2.0 Gy/fraction; five fractions/week; total of five fractions), or a combination of anti-EGFR-iRGD and ionizing radiation. As shown in Fig. 4A, treatment with radiation alone or anti-EGFR-iRGD alone produced modest inhibition of tumor growth in BGC-823 xenografts. However, when combined with radiation, anti-EGFR-iRGD enhanced the tumor growth inhibition profile over the 24-day observation period.

In vivo expression of proliferating cellular nuclear antigen, apoptosis and necrosis. BGC-823 tumor xenografts were used for evaluation of the expression of markers of tumor proliferation (Ki-67). The immunohistochemical staining for
Ki-67 indicated that the number of proliferating cells were the lowest in the combined treatment group, intermediate in the groups receiving single modality treatment with either anti-EGFR-iRGD or radiation, and highest in the control group. Furthermore, TUNEL staining results showed that the number of apoptotic cells in the combined treatment group was marginally higher than that in the radiotherapy group and the fusion protein group. However, there was no statistically significant difference between three treated groups because the F statistic of one-way ANOVA was 1.679 with $\mathrm{P}=0.227>0.05$ (The $\mathrm{F}$ statistic of the variance homogeneity test between tree groups was 0.344 with $\mathrm{P}=0.716>0.05)$. The pathological examination showed tumor necrosis in all treatment groups. However, the necrotic area of the PBS-treated control group was the smallest, whereas the anti-EGFR-iRGD and radiation-treated groups had larger necrotic regions. The largest necrotic regions were apparent in the combined treatment group. These results demonstrated the capacity of anti-EGFR-iRGD in modulating cellular proliferation and cell necrosis (Fig. 4B).

Side effects of anti-EGFR-iRGD with ionizing radiation. As shown in Fig. $5 \mathrm{~A}$, none of the mice treated with 
A

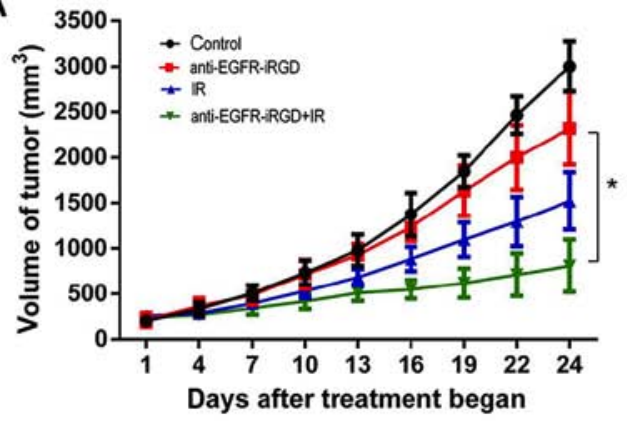

B
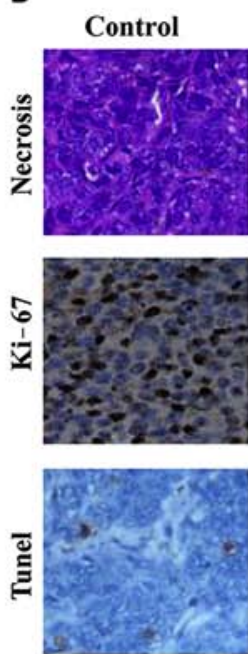

anti-EGFR-

iRGD
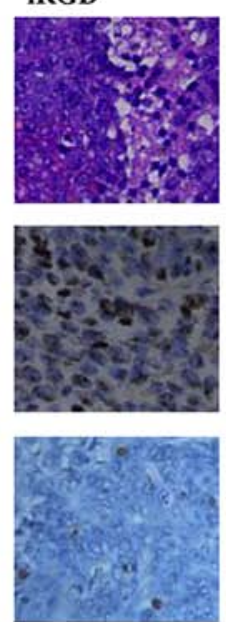
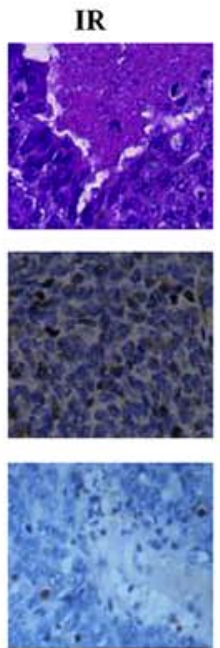

anti-EGFR-

iRGD+IR
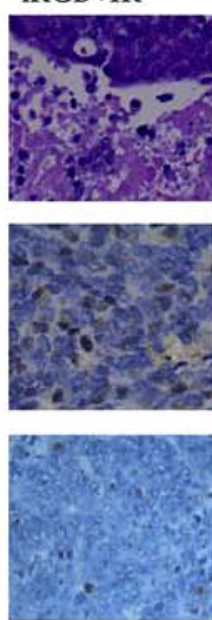

Figure 4. Inhibitory effect of anti-EGFR-iRGD in combination with IR on tumor growth in mice. (A) Tumor growth curves. Mice bearing subcutaneous BGC-823 were treated with PBS, anti-EGFR-iRGD, IR, or anti-EGFR-iRGD combined with IR. Data are presented as the mean \pm standard error of the mean $(\mathrm{n}=5)$. One-way analysis of variance was used for the analysis of tumor growth $(" \mathrm{P}<0.05)$. (B) Evaluation of cell necrosis, and the antiproliferative effect of anti-EGFR-iRGD combined with radiation in BGC-823 tumors 24 days post-treatment. Cell necrosis was evaluated by hematoxylin and eosin staining (magnification, x100) of tumor sections, whereas cell proliferation was evaluated by immunohistochemistry of Ki-67. Cell death was evaluated by immunohistochemistry using TUNEL (magnification, x100), there was no statistically significant difference between three treated groups. EGFR, epidermal growth factor receptor; IR, ionizing radiation.

A

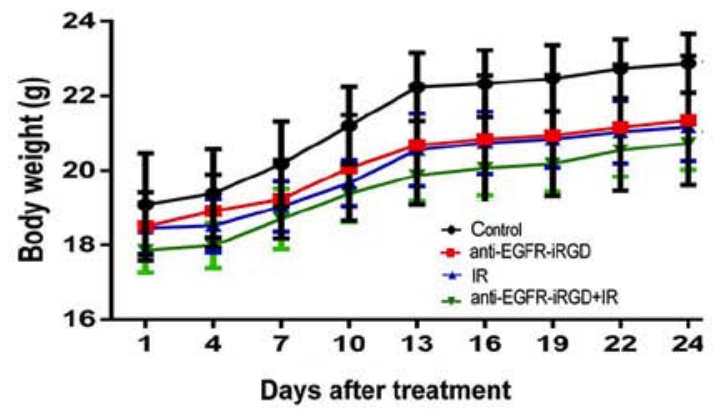

B
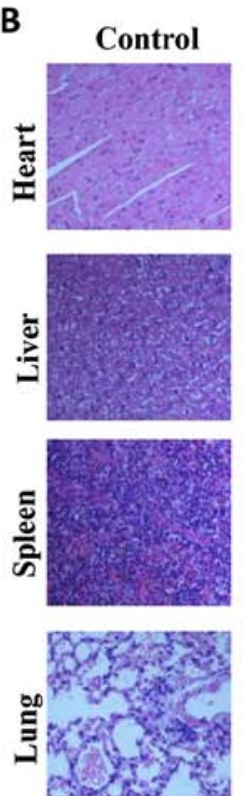

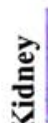

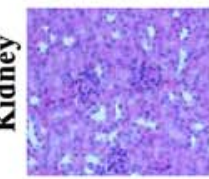

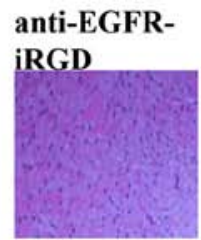
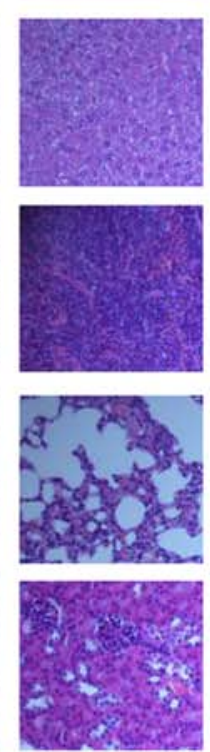

IR
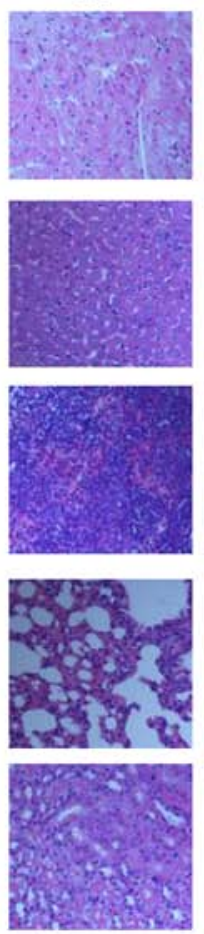

anti-EGFR-
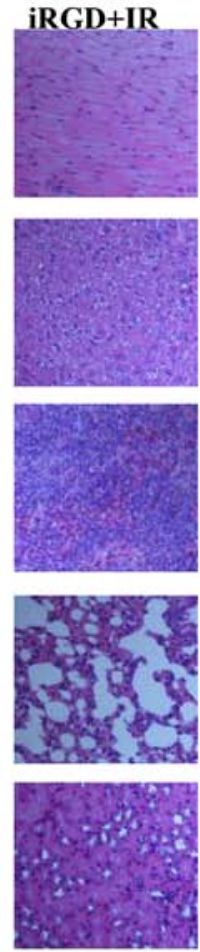

Figure 5. Side effects of anti-EGFR-iRGD in combination with IR. (A) Changes in body weight. Data are presented as the mean \pm standard error of the mean $(n=5)$. One-way analysis of variance was used for the analysis of body weight; $(\mathrm{P}>0.05)$. (B) Heart, liver, spleen, lungs and kidneys were dissected for hematoxylin and eosin staining on day 24 post-treatment. Tissue changes involved minimal inflammatory cells infiltrating in the spleen, with no significant abnormal damage were observed (magnification, x200). EGFR, epidermal growth factor receptor; IR, ionizing radiation.

anti-EGFR-iRGD, ionizing radiation or combination treatment showed any body weight loss. The mean body weights of mice in the three treatment groups were marginally lower than that of mice in the control group, however, no significant differences were observed in body weight between the four groups by covariance analysis $(\mathrm{P}=0.174>0.05)$. The $\mathrm{H} \& \mathrm{E}$ staining of the organs (Fig. 5B) showed that tissue changes comprised only the presence of inflammatory cells that infiltrated the spleen. 
No significant damage was observed in the heart, liver, lung or kidney.

\section{Discussion}

In our previous study, it was demonstrated that the recombinant protein anti-EGFR-iRGD exhibited antitumor activity in gastric cancer cell lines, multicellular spheroids, and mice (16). In the present study, the capacity of anti-EGFR-iRGD to modulate the radiation response of human gastric cancer cell lines and xenografts was investigated. Previous studies have indicated a favorable antitumor interaction between radiation and EGFR inhibitors (18-20). It was suggested that this enhanced effect may explain the levels of EGFR activation during cell cycle kinetics and radiation, which may contribute to the inhibition of accelerated cellular repopulation.

EGFR is a receptor tyrosine kinase that belongs to the ErbB family. The overexpression or upregulation of EGFR is generally associated with an adverse outcome (21-23). EGFR can also be activated by radiotherapy $(24,25)$. Mechanistically, high levels of EGFR are reported to enable tumor cells to be more radioresistant for the activation of downstream signals (26). The EGFR downstream signal transduction pathways, through the PI3K/AKT or Ras/Raf/MAPK pathways, have proven to be efficient regulators of cancer gene expression, cell cycle progression, cell proliferation, angiogenesis, invasion and metastasis (27). Therefore, EGFR has been considered as a key target in anticancer treatments, particularly in combination with radiotherapy. Two classes of pharmacological EGFR inhibitors have been used clinically: TKIs and monoclonal antibodies (28). In several studies, it was reported that the overexpression of EGFR was correlated with lower tumor control rates following radiation $(29,30)$, however, conflicting results have also been reported (31-33).

The interaction between radiation and levels of EGFR was first described $>20$ years ago. Early studies showed that prolonged exposure to EGF increased the cytotoxic effects of radiation $(34,35)$. Translational studies in patients have shown that the overexpression of EGFR was correlated with radioresistance (36). The mechanism of EGFR inhibitors combined with radiosensitization is complex. In response to radiation, three distinct phases in the effect of EGFR have been elucidated. These phases include activation of pro-survival pathways, enhanced cell proliferation, and the role of EGFRs in DNA repair $(37,38)$. An explanation for radiosensitization may be that the tumor repopulation is limited by the cytostatic effect of EGFR inhibition during fractionation radiotherapy. Other studies have suggested that radiosensitivity may be more complex than the induction of cell cycle arrest alone. In previous studies, it was shown that cetuximab promoted radiation-induced apoptosis and impaired sublethal damage to DNA repair, thereby affecting the nuclear translocation of DNA-PK (39). The effect of radiation on the activation of EGFR is most pronounced in serum-starved or confluent cells (24). Studies have shown that the radiosensitivity of quiescent and proliferating cells is different from that of the inhibition of EGFR. Specifically, in quiescent cells radiation induces the transient activation of EGFR, resulting in $\mathrm{S}$ phase progression, impaired DNA repair and enhanced cell death (40). The inhibition of EGFR may protect cells in the first few hours following radiation, whereas the combined effects of G1 arrest and DNA repair inhibition may result in increased sensitization $24 \mathrm{~h}$ following inhibition.

Although EGFR has often been described as a cell surface receptor, it is closely associated with several nuclear processes. In addition, resistance to radiation has been associated with nuclear levels of EGFR (38). Nuclear EGFR signaling is important in gene regulation, but also affects DNA repair. Nuclear EGFR is involved in resistance to EGFR-targeted therapies. In addition to the classic mechanism of DNA damage, high dose per fraction radiation ( $>8 \mathrm{~Gy}$ ) may generate stromal effects that are not accounted for in traditional radiobiological modeling (41). Anti-EGFR-iRGD, which specifically targets EGFR, spreads extensively throughout the tumor mass. Furthermore, following radiation for $24 \mathrm{~h}$, anti-EGFR-iRGD appear to permeate even further into the tumor tissue. The combination of an increased degree and/or different modes of DNA damage and injury to the tumor microenvironment arising from the use of hypofractionation may work synergistically to cause irreparable and lethal injuries to irradiated tumor cells $(41,42)$.

For EGFR-targeted therapies to be successful, appropriate patient selection is required to optimize efficacy. The RTOG 0617 study showed the importance of patient selection when EGFR-targeted therapy with radiotherapy was used (43). Significant progress has been made in the development of novel radiation approaches. However, the integration of targeted therapy and radiotherapy has raised several unresolved questions, including the identification of patients, optimal dose and time of radiation, treatment sequence, and side effects of treatment. Therefore, further investigations are required to better analyze targeted therapies and, in particular, the combination of antibodies and radiotherapy.

In conclusion, given the importance of EGFR in several types of cancer and the well-defined role of EGFR in the response to radiotherapy, this receptor is an important target when treatment is combined with radiotherapy. The present study demonstrated that anti-EGFR-iRGD was an effective radiosensitizer in EGFR-overexpressing gastric cancer cells and xenografts. The radioenhancement in gastric cancer cells and xenografts was associated with inhibited radiation-induced upregulation of EGFR, inhibited cell proliferation and promotion of cell apoptosis. In conclusion, anti-EGFR-iRGD was a selective and effective radiosensitizer in gastric cancer, which makes it a potential superior EGFR-targeted therapy for further preclinical and clinical use.

\section{Acknowledgements}

Not applicable.

\section{Funding}

The present study was supported by the National Key Research and Development Program of China (grant no. 2017YFC1308900), the National Natural Science Foundation of China (grant nos. 81502037, 81572601, 81672367 and 81220108023) and the Natural Science Foundation of Jiangsu Province (grant no. BK20151095). 


\section{Availability of data and materials}

The datasets analyzed in the present study are available from the corresponding author on reasonable request.

\section{Authors' contributions}

BL, QL, HS and FJ conceived and designed the study. FM, $\mathrm{AZ}, \mathrm{ND}, \mathrm{HZ}, \mathrm{HQ}$ and LY were involved in the experiments and drafted the manuscript. HX performed the statistical analysis. BL, QL, HS and FJ wrote and revised the manuscript. All authors read and approved the manuscript and agree to be accountable for all aspects of the research in ensuring that the accuracy or integrity of any part of the work are appropriately investigated and resolved.

\section{Ethics approval and consent to participate}

The study protocol was reviewed and approved by the Ethics Committee of Nanjing Drum Tower Hospital, The Affiliated Hospital of Nanjing University Medical School.

\section{Patient consent for publication}

Not applicable.

\section{Competing interests}

The authors declare that they have no competing interests.

\section{References}

1. Shen L, Shan YS, Hu HM, Price TJ, Sirohi B, Yeh KH, Yang YH, Sano T, Yang HK, Zhang X, et al: Management of gastric cancer in Asia: Resource-stratified guidelines. Lancet Oncol 14: e535-e547, 2013

2. Jemal A, Bray F, Center MM, Ferlay J, Ward E and Forman D: Global cancer statistics. CA Cancer J Clin 61: 69-90, 2011.

3. Henning GT, Schild SE, Stafford SL, Donohue JH, Burch PA, Haddock MG and Gunderson LL: Results of irradiation or chemoirradiation for primary unresectable, locally recurrent, or grossly incomplete resection of gastric adenocarcinoma. Int J Radiat Oncol Biol Phys 46: 109-118, 2000.

4. Jansen EP, Boot H, Verheij M and van de Velde CJ: Optimal locoregional treatment in gastric cancer. J Clin Oncol 23 . 4509-4517, 2005.

5. Smalley SR, Gunderson L, Tepper J, Martenson JA Jr, Minsky B, Willett $\mathrm{C}$ and Rich T: Gastric surgical adjuvant radiotherapy consensus report: Rationale and treatment implementation. Int J Radiat Oncol Biol Phys 52: 283-293, 2002.

6. Salomon DS, Brandt R, Ciardiello F and Normanno N: Epidermal growth factor-related peptides and their receptors in human malignancies. Crit Rev Oncol Hematol 19: 183-232, 1995.

7. Kim MA, Lee HS, Lee HE, Jeon YK, Yang HK and Kim WH: EGFR in gastric carcinomas: Prognostic significance of protein overexpression and high gene copy number. Histopathology 52: 738-746, 2008

8. Herbst RS: Review of epidermal growth factor receptor biology. Int J Radiat Oncol Biol Phys 59 (Suppl 2): S21-S26, 2004.

9. Baumann M and Krause M: Targeting the epidermal growth factor receptor in radiotherapy: Radiobiological mechanisms, preclinical and clinical results. Radiother Oncol 72: 257-266, 2004.

10. Chinnaiyan P, Huang S, Vallabhaneni G, Armstrong E, Varambally S, Tomlins SA, Chinnaiyan AM and Harari PM: Mechanisms of enhanced radiation response following epidermal growth factor receptor signaling inhibition by erlotinib (Tarceva). Cancer Res 65: 3328-3335, 2005.
11. Bonner JA, Harari PM, Giralt J, Azarnia N, Shin DM, Cohen RB, Jones CU, Sur R, Raben D, Jassem J, et al: Radiotherapy plus cetuximab for squamous-cell carcinoma of the head and neck. N Engl J Med 354: 567-578, 2006.

12. Harari $P$ and Huang S: Radiation combined with EGFR signal inhibitors: Head and Neck cancer focus. Semin Radiat Oncol 16: 38-44, 2006.

13. Lammering G: Molecular predictor and promising target: Will EGFR now become a star in radiotherapy? Radiother Oncol 74: 89-91, 2005.

14. Yewale C, Baradia D, Vhora I, Patil S and Misra A: Epidermal growth factor receptor targeting in cancer: A review of trends and strategies. Biomaterials 34: 8690-8707, 2013.

15. Bell A, Wang ZJ, Arbabi-Ghahroudi M, Chang TA, Durocher Y, Trojahn U, Baardsnes J, Jaramillo ML, Li S, Baral TN, et al: Differential tumor-targeting abilities of three single-domain antibody formats. Cancer Lett 289: 81-90, 2010.

16. Sha H, Zou Z, Xin K, Bian X, Cai X, Lu W, Chen J, Chen G, Huang L, Blair AM, et al: Tumor-penetrating peptide fused EGFR single-domain antibody enhances cancer drug penetration into 3D multicellular spheroids and facilitates effective gastric cancer therapy. J Control Release 200: 188-200, 2015.

17. Balkwill FR and Mantovani A, Cancer-related inflammation: Common themes and therapeutic opportunities, Semin Cancer Biol 22: 33-40, 2012.

18. Huang SM, Li J, Armstrong EA and Harari PM: Modulation of radiation response and tumor-induced angiogenesis after epidermal growth factor receptor inhibition by ZD1839 (Iressa). Cancer Res 62: 4300-4306, 2002.

19. Milas L, Mason K, Hunter N, Petersen S, Yamakawa M, Ang K, Mendelsohn J and Fan Z: In vivo enhancement of tumor radioresponse by $\mathrm{C} 225$ antiepidermal growth factor receptor antibody. Clin Cancer Res 6: 701-708, 2000.

20. Bianco C, Tortora G, Bianco R, Caputo R, Veneziani BM, Caputo R, Damiano V, Troiani T, Fontanini G, Raben D, et al: Enhancement of antitumor activity of ionizing radiation by combined treatment with the selective epidermal growth factor receptor-tyrosine kinase inhibitor ZD1839 (Iressa). Clin Cancer Res 8: 3250-3258, 2002.

21. Eriksen JG, Steiniche T and Overgaard J; Danish Head and Neck Cancer study group (DAHANCA): The influence of epidermal growth factor receptor and tumor differentiation on the response to accelerated radiotherapy of squamous cell carcinomas of the head and neck in the randomized DAHANCA 6 and 7 study. Radiother Oncol 74: 93-100, 2005.

22. Bentzen SM, Atasoy BM, Daley FM, Dische S, Richman PI, Saunders MI, Trott KR and Wilson GD: Epidermal growth factor receptor expression in pretreatment biopsies from head and neck squamous cell carcinoma as a predictive factor for a benefit from accelerated radiation therapy in a randomized controlled trial. J Clin Oncol 23: 5560-5567, 2005.

23. Mendelsohn $\mathrm{J}$ and Baselga J: Epidermal growth factor receptor targeting in cancer. Semin Oncol 33: 369-385, 2006.

24. Schmidt-Ullrich RK, Mikkelsen RB, Dent P, Todd DG, Valerie K, Kavanagh BD, Contessa JN, Rorrer WK and Chen PB: Radiation-induced proliferation of the human A431 squamous carcinoma cells is dependent on EGFR tyrosine phosphorylation. Oncogene 15: 1191-1197, 1997.

25. Sturla LM, Amorino G, Alexander MS, Mikkelsen RB, Valerie K and Schmidt-Ullrichr RK: Requirement of Tyr-992 and Tyr-1173 in phosphorylation of the epidermal growth factor receptor by ionizing radiation and modulation by SHP2. J Biol Chem 280: 14597-14604, 2005.

26. Huang SM, Bock JM and Harari PM: Epidermal growth factor receptor blockade with $\mathrm{C} 225$ modulates proliferation, apoptosis, and radiosensitivity in squamous cell carcinomas of the head and neck. Cancer Res 59: 1935-1940, 1999.

27. Marmor MD, Skaria KB and Yarden Y: Signal transduction and oncogenesis by ErbB/HER receptors. Int J Radiat Oncol Biol Phys 58: 903-913, 2004.

28. Ciardiello F and Tortora G: A novel approach in the treatment of cancer: Targeting the epidermal growth factor receptor. Clin Cancer Res 7: 2958-2970, 2001.

29. Gibson MK, Abraham SC, Wu TT, Burtness B, Heitmiller RF, Heath E and Forastiere A: Epidermal growth factor receptor, p53 mutation, and pathological response predict survival in patients with locally advanced esophageal cancer treated with preoperative chemoradiotherapy. Clin Cancer Res 9: 6461-6468, 2003. 
30. Giralt J, de las Heras M, Cerezo L, Eraso A, Hermosilla E, Velez D, Lujan J, Espin E, Rosello J, Majó J, et al: The expression of epidermal growth factor receptor results in a worse prognosis for patients with rectal cancer treated with preoperative radiotherapy: A multicenter, retrospective analysis. Radiother Oncol 74: 101-108, 2005.

31. Chakravarti A, Seiferheld W, Tu X, Wang H, Zhang HZ, Ang KK, Hammond E, Curran W Jr and Mehta M: Immunohistochemically determined total epidermal growth factor receptor levels not of prognostic value in newly diagnosed glioblastoma multiforme: Report from the radiation therapy oncology group. Int J Radiat Oncol Biol Phys 62: 318-327, 2005.

32. Chakravarti A, Winter K, Wu CL, Kaufman D, Hammond E, Parliament M, Tester W, Hagan M, Grignon D, Heney N, et al: Expression of the epidermal growth factor receptor and Her-2 are predictors of favorable outcome and reduced complete response rates, respectively, in patients with muscle-invading bladder cancers treated by concurrent radiation and cisplatin-based chemotherapy: A report from the Radiation Therapy Oncology Group. Int J Radiat Oncol Biol Phys 62: 309-317, 2005.

33. Lee CM, Shrieve DC, Zempolich KA, Lee RJ, Hammond E, Handrahan DL and Gaffney DK: Correlation between human epidermal growth factor receptor family (EGFR, HER2, HER3, HER4), phosphorylated Akt (P-Akt), and clinical outcomes after radiation therapy in carcinoma of the cervix. Gynecol Oncol 99: 415-421, 2005.

34. Bonner JA, Maihle NJ, Folven BR, Christianson TJ and Spain K: The interaction of epidermal growth factor and radiation in human head and neck squamous cell carcinoma cell lines with vastly different radiosensitivities. Int J Radiat Oncol Biol Phys 29: 243-247, 1994.

35. Kwok TT and Sutherland RM: Enhancement of sensitivity of human squamous carcinoma cells to radiation by epidermal growth factor. J Natl Cancer Inst 81: 1020-1024, 1989.
36. Zhu A, Shaeffer J, Leslie S, Kolm P and El-Mahdi AM: Epidermal growth factor receptor: An independent predictor of survival in astrocytic tumors given definitive irradiation. Int J Radiat Oncol Biol Phys 34: 809-815, 1996.

37. Nyati MK, Morgan MA, Feng FY and Lawrence TS: Integration of EGFR inhibitors with radiochemotherapy. Nat Rev Cancer 6: 876-885, 2006.

38. Chen DJ and Nirodi CS: The epidermal growth factor receptor: A role in repair of radiation-induced DNA damage. Clin Cancer Res 13: 6555-6560, 2007.

39. Harari PM and Huang SM: Epidermal growth factor receptor modulation of radiation response: Preclinical and clinical development. Semin Radiat Oncol 12 (Suppl 2): S21-S26, 2002.

40. Ahsan A, Hiniker SM, Davis MA, Lawrence TS and Nyati MK: Role of cell cycle in epidermal growth factor receptor Inhibitor-mediated radiosensitization. Cancer Res 69: 5108-5114, 2009.

41. Brown JM and Koong AC: High-dose single-fraction radiotherapy: Exploiting a new biology? Int J Radiat Oncol Biol Phys 71: 324-325, 2008.

42. Gerszten PC, Mendel E and Yamada Y: Radiotherapy and radiosurgery for metastatic spine disease: What are the options, indications, and outcomes? Spine (Phila Pa 1976) 34 (Suppl 22): S78-S92, 2009

43. Bradley JD, Paulus R, Komaki R, Masters G, Blumenschein G, Schild S, Bogart J, Hu C, Forster K, Magliocco A, et al: Standard-dose versus high-dose conformal radiotherapy with concurrent and consolidation carboplatin plus paclitaxel with or without cetuximab for patients with stage IIIA or IIIB non-small-cell lung cancer (RTOG 0617): A randomised, two-by-two factorial phase 3 study. Lancet Oncol 16: 187-199, 2015. 